\title{
A Subsidized Healthy Food Prescription Program for Adults with type 2 Diabetes who are Experiencing Food Insecurity: Protocol for a Randomized Controlled Trial, Modelling and Implementation Studies
}

\section{Dana Lee Olstad ( $\square$ dana.olstad@ucalgary.ca )}

University of Calgary Cumming School of Medicine https://orcid.org/0000-0001-9787-9952

\section{Reed F Beall}

University of Calgary Cumming School of Medicine

\section{Eldon Spackman}

University of Calgary Cumming School of Medicine

\section{Sharlette Dunn}

University of Calgary Cumming School of Medicine

\section{Lorraine Lipscombe}

University of Toronto Faculty of Medicine: University of Toronto Temerty Faculty of Medicine

\section{Kienan Williams}

Alberta Health Services

\section{Richard T Oster}

University of Alberta Department of Agricultural Food and Nutritional Science

\section{Sara Scott}

University of Calgary Faculty of Medicine: University of Calgary Cumming School of Medicine

\section{Gabrielle L Zimmermann}

University of Calgary Faculty of Medicine: University of Calgary Cumming School of Medicine

\section{Kerry A McBrien}

University of Calgary Cumming School of Medicine

\section{Kieran JD Steer}

University of Calgary Cumming School of Medicine

\section{Catherine B Chan}

University of Alberta Department of Agricultural Food and Nutritional Science

\section{Sheila Tyminski}

\section{Alberta Health Services}

\section{Seth A Berkowitz}

University of North Carolina at Chapel Hill School of Medicine

\section{Alun L Edwards}

University of Calgary Faculty of Medicine: University of Calgary Cumming School of Medicine

\section{Terry Saunders-Smith}

University of Calgary Cumming School of Medicine

\section{Saania Tariq}


University of Calgary Faculty of Medicine: University of Calgary Cumming School of Medicine

\section{Naomi Popeski}

Alberta Health Services

\section{Laura White}

Indigenous Services Canada

\section{Tyler Williamson}

University of Calgary Cumming School of Medicine

\section{Mary R L'Abbe}

University of Toronto Faculty of Medicine: University of Toronto Temerty Faculty of Medicine

\section{Kim D Raine}

University of Alberta School of Public Health

\section{Sara Nejatinamini}

University of Calgary Cumming School of Medicine

\section{Aruba Naser}

University of Calgary Cumming School of Medicine

\section{Carlota Basualdo-Hammond}

Alberta Health Services

\section{Colleen Norris}

University of Alberta Faculty of Nursing

\section{Petra O’Connell}

Alberta Health Services

\section{Judy Seidel}

University of Calgary Cumming School of Medicine

\section{Jason Cabaj}

University of Calgary Cumming School of Medicine

\section{David JT Campbell}

University of Calgary Cumming School of Medicine

\section{Study protocol}

Keywords: Type 2 diabetes, Food insecurity, Hyperglycemia, Diet quality, Food subsidies, Diabetes complications, Cost-effectiveness, Randomized controlled trial, Implementation study, Modelling study

Posted Date: February 10th, 2021

DOI: https://doi.org/10.21203/rs.3.rs-180761/v1

License: (c) (P) This work is licensed under a Creative Commons Attribution 4.0 International License. Read Full License 


\section{Abstract}

Background: The high cost of many healthy foods poses a significant challenge to the maintenance of optimal blood glucose levels for adults with type 2 diabetes (T2DM) who are experiencing food insecurity, leading to diabetes complications and excess acute care usage and costs. Subsidized healthy food prescription programs may help to reduce food insecurity by financially supporting patients to improve their diet quality, prevent diabetes complications and avoid acute care use. This study will use a type 2 hybrid effectivenessimplementation design to examine the reach, effectiveness, adoption, implementation and maintenance (RE-AIM) of a subsidized healthy food prescription program for adults who are experiencing food insecurity and persistent hyperglycemia. A randomized controlled trial (RCT) will investigate program effectiveness via impact on blood glucose levels (primary outcome), food insecurity, diet quality and other clinical and patient-reported outcomes. A modelling study will estimate longer-term program effectiveness in reducing diabetes-related complications, resource use and costs. An implementation study will examine all RE-AIM domains, including reasons behind program successes and failures, fidelity, mechanisms of impact, contextual determinants of effective implementation and sustainability.

Methods: 404 adults who are experiencing food insecurity and persistent hyperglycemia, including adults who identify as Indigenous, will be randomized to a subsidized healthy food prescription intervention $(n=202)$ or a healthy food prescription comparison group $(n=202)$. Both groups will receive a healthy food prescription. The intervention group will additionally receive $\$ 1.50 /$ day/household member to purchase healthy foods in supermarkets for 6 months. The implementation process will follow the Quality Implementation Framework. Outcomes will be assessed at baseline and follow-up ( 6 months) in the RCT and analyzed using mixed-effects linear and multinomial logistic/ordinal regression models. Longer-term outcomes will be modelled using the validated UK Prospective Diabetes Study outcomes simulation model-2. Implementation processes and outcomes will be continuously measured via quantitative and qualitative data and analyzed using descriptive statistics and theory-informed directed content analysis, respectively.

Discussion: This research will provide a comprehensive body of data with high internal and external validity to assist policymakers and practitioners to effectively and rapidly translate the evidence generated into programs and policies to support patients with T2DM who are experiencing food insecurity.

Trial registration: ClinicalTrials.gov NCT04725630 (January 25, 2021;

https://www.clinicaltrials.gov/ct2/show/NCT04725630?

term=Subsidized+Healthy+Food+Prescription+Program\&cond=Diabetes+Mellitus\%2C+Type+2\&draw=2\&rank=1).

\section{Contributions To The Literature}

- The high cost of many healthy foods poses a barrier to maintaining a healthy dietary pattern for adults who are experiencing food insecurity.

- We will investigate the reach, effectiveness, adoption, implementation and maintenance of a subsidized healthy food prescription program for adults who are experiencing food insecurity and persistent hyperglycemia.

- A RCT and a modelling study will demonstrate the short- and longer-term impacts of the program on blood glucose levels, other health-related outcomes, resource use and costs. 
- An implementation study will support translation of findings into practice by demonstrating reasons behind program successes and failures, mechanisms of action and determinants of effective implementation.

\section{Background}

Type 2 diabetes (T2DM) imposes a tremendous burden on healthcare systems worldwide, as individuals with T2DM incur twice the healthcare costs as their age- and sex-matched counterparts [1, 2]. The total economic costs of diabetes were $\$ 327$ billion in 2017 in the US, and $\$ 30$ billion in Canada in 2019, making it among the most expensive chronic conditions in both nations $[1,3,4]$. The human toll on individuals and their families is also substantial in terms of reduced quality of life associated with managing the disease $[5,6]$. Many of these human and economic costs are avoidable, as adherence to a healthy diet within an overall diabetes management plan can yield clinically meaningful improvements in blood glucose levels, which can reduce diabetes complications over time [7-15]. Average blood glucose levels are most often quantified using the glycosylated hemoglobin level (A1C), which represents the average blood sugar level over the previous 3 months [16]. An absolute reduction of $0.5 \%$ in $\mathrm{A} 1 \mathrm{C}$ is achievable through improving diet quality $[7,8]$ and is considered a clinically meaningful difference [17].

The high and continually escalating costs of many healthy foods $[18,19]$ represents a formidable barrier to adhering to a healthy dietary pattern for individuals with T2DM, particularly for those who are experiencing food insecurity [20-24]. Food insecurity refers to inadequate or insecure access to food due to financial constraints [25] and is a strong predictor of high-cost healthcare use [26]. Evidence indicates that individuals with T2DM who are experiencing food insecurity have lower diet quality than their food secure counterparts, leading to elevations in blood glucose levels [27-35], and high rates of diabetes complications and acute care use [29, 32, 36-39]. Indigenous groups (constitutionally recognized as First Nations, Inuit and Métis) are a population of particular concern, given their disproportionately high rates of both T2DM and food insecurity [40-42]. The coexistence of food insecurity and T2DM therefore has major implications for the sustainability of healthcare systems.

Although it is well-known that food insecurity is a primary driver of acute care usage and costs, healthcare providers often lack effective strategies to address it. One approach to better address this problem is to assist patients who are experiencing food insecurity to purchase diabetes-appropriate foods through subsidized healthy food prescription programs. Preliminary evidence suggests that these programs may improve diet quality and self-reported health, while reducing food insecurity, hypertension and BMI, including within Indigenous communities [43-57]. Notably, one $\$ 40$ fruit and vegetable subsidy delivered to 65 low-income patients with persistent hyperglycemia over 13 weeks led to a $0.71 \%$ decline in A1C [56]. Qualitative data similarly suggest patients and care providers perceive financial, dietary and health benefits from these programs, and support their ongoing delivery $[43,50,58-60]$. Food prescription programs also appear to be cost-effective, with one recent modelling study indicating that a national subsidized healthy food prescription program in the US could eliminate $\$ 100.2$ billion in healthcare costs if implemented over the lifetime of beneficiaries [61].

Despite some promising initial findings, major knowledge gaps remain pertaining to the impact and optimal implementation of subsidized healthy food prescription programs. Most prior studies have been small and uncontrolled, and have examined a small number of self-reported outcomes using brief dietary $[44,45,48,60,62]$ and/or food insecurity screeners [47, 50-53], and/or short descriptive surveys $[44,58,60]$, rather than objective clinical outcomes. Prior programs have also subsidized the purchase of fruits and vegetables alone, without 
considering the relevance of entire dietary patterns to blood glucose levels and health outcomes [7, 8]. Moreover, there is virtually no understanding of the effectiveness and cost-effectiveness of these programs over the longer term, nor of optimal implementation strategies [63].

We will build upon these initial findings through three concurrent studies, including a randomized controlled trial (RCT), a modelling study and an implementation study, using a type 2 hybrid effectiveness-implementation design [64]. Collective findings will be integrated to provide a comprehensive perspective of the reach, effectiveness, adoption, implementation and maintenance (RE-AIM) $[65,66]$ of a subsidized healthy food prescription program among adults who are experiencing food insecurity and persistent hyperglycemia. First, the RCT will provide a basis for causal inference pertaining to program effectiveness. It will entail a broad food subsidy applicable to all major food groups, and will be powered to detect clinically meaningful changes in A1C, along with a comprehensive range of objective and self-reported health-related outcomes. A linked modelling study will provide a longer-term perspective of program effectiveness in reducing diabetes-related complications, along with healthcare use and costs. Finally, a complementary implementation study will encompass quantitative and qualitative measures of all RE-AIM domains to support translation of research findings into practice and policy by helping to understand reasons behind program successes and failures, implementation fidelity, mechanisms of impact, contextual determinants of effective implementation and the likelihood of sustainability.

\section{Methods}

\section{Overview}

\section{Ethics, privacy and confidentiality}

This research has been approved by the University of Calgary Conjoint Health Research Ethics Board (REB200543) and the University of Alberta Health Research Ethics Board Biomedical Panel (Pro00107116). Any protocol deviations will be approved in advance by the Board and updated in the clinical trials registry. All participants will provide written, informed consent prior to data collection (Additional file 1). Participant data will be anonymized and stored on a password protected University server. Only the Principal Investigators and Research Coordinators will have access to identifiable participant information and the final trial datasets.

\section{Setting}

This research will take place in Alberta, Canada. Participants will be recruited through primary care and diabetes specialty clinics located in urban and rural communities, including clinics with an explicit focus on serving people identifying as Indigenous.

\section{Study oversight}

\section{Scientific Steering Committee}


A Scientific Steering Committee will oversee all aspects of the research, receive and review reports from the study's Advisory Boards and Subcommittees, and will have final decision-making authority. It will be comprised of the study's five co-Principal Investigators (DLO, ES, RFB, LL, DJTC).

\section{Advisory Board}

A multi-stakeholder Advisory Board will provide high-level oversight for the research and will advise the Scientific Steering Committee on study conduct. Members will include policymakers, academic experts, representatives from Alberta Health Services (the provincial health authority), an Indigenous public health expert and a patient.

\section{Indigenous Advisory Board}

An Indigenous Advisory Board will ensure that research activities within Indigenous clinics proceed in a culturally sensitive, relevant, responsive, equitable and reciprocal manner that is guided by OCAP (Indigenous Ownership, Control, Access and Possession of data) principles [67] and complies with Government of Canada guidance for Indigenous Research $[68,69]$. The Board will include Indigenous Elders and patients, along with academic experts, policymakers, managers and front-line practitioners from the public health and healthcare sectors who are themselves Indigenous, or who work closely with Indigenous peoples.

\section{Primary Care Clinic Subcommittee}

The Primary Care Clinic (PCC) Subcommittee will include PCC managers, staff and patients. As participant recruitment and implementation of the intervention unfolds, PCC managers and staff will collect feedback from their respective clinics and will share it with the larger group as a learning tool and to inform ongoing adaptations.

\section{Implementation Support Team}

The Implementation Support Team will consist of Research Coordinators and Assistants who will execute the daily tasks required to administer, plan, support, monitor and evaluate the subsidized healthy food prescription program.

\section{Patient and public involvement}

This research has been informed by substantial prior [70-74] and ongoing engagement with patients experiencing financial barriers to chronic disease care. Patients (who are not study participants) will help to pilot test infrastructural supports (e.g. healthy food prescription pamphlet, usability of the subsidy list), care pathways and implementation processes, and will be members of the Advisory Boards and PCC Subcommittee. Patients who are study participants will provide continuous program feedback via a dedicated study help-line/email, and by completing implementation fidelity checklists. At the conclusion of the study, participants will be invited to describe their program experiences via a post-intervention questionnaire and during in-depth, semi-structured interviews. 
Lands and food hold deep cultural, symbolic and spiritual significance for Indigenous peoples [75]. Staff and patients from Indigenous PCCs will co-design clinical care pathways and other procedures that are contextspecific and culturally appropriate for Indigenous patients, and that respect and promote Indigenous worldviews, particularly those surrounding food procurement and consumption. We will ensure that representatives from Indigenous clinics are involved at all stages of the research, including study design, pilot testing infrastructural supports, interpreting results and formulating conclusions, and that their agreement is obtained prior to communicating any research findings that pertain to them. As previously described, the Indigenous Advisory Board will also oversee all aspects of the research.

\section{Evaluation framework and theory of change}

RE-AIM $[65,66]$ will provide a structured means of integrating data from the RCT, modelling and implementation studies to understand the reach, effectiveness, adoption, implementation and maintenance of the subsidized healthy food prescription program.

Our theory of change draws on Barnard et al's [76] conceptual model linking material needs insecurities with diabetes outcomes, and posits that reduced food insecurity and improved diet quality will be key mediators of improved blood glucose levels, which will help to reduce diabetes complications, and healthcare resource use and costs. Each construct will be examined to affirm or disprove the proposed pathway (Figure 1).

\section{Randomized controlled trial}

The RCT protocol adheres to the SPIRIT and TIDieR reporting guidelines (Table 1; Additional File 2-4).

\section{Study design and objectives}

A 6 month, parallel-group RCT will examine the effectiveness of a subsidized healthy food prescription program, compared to a healthy food prescription alone, in improving the following outcomes among 404 adults who are experiencing food insecurity and persistent hyperglycemia (i.e. A1C 8-12\%):

1) Primary outcome: Average blood glucose levels measured by A1C

2) Secondary outcomes:

a. Blood glucose levels: Proportion of patients with elevated A1C (i.e. $\geq 9 \%$ ); blood glucose measured by fructosamine

b. Dietary intake: Diet quality; skin carotenoids

c. Intermediate clinical outcomes: Blood lipids; blood pressure; body mass index (BMI); waist circumference; need for diabetes medication/insulin

d. Patient-reported outcomes: Psychosocial well-being; self-rated health; diabetes self-efficacy; diabetes selfmanagement; diabetes distress; diabetes competing demands; perceived financial barriers to chronic disease care; hypoglycemic episodes; household food insecurity 
3) Exploratory outcomes: Subjective social status; perceived income adequacy; work productivity and activity impairment; medication and physical activity adherence

\section{Primary care clinics}

PCCs will be recruited, including urban, rural and Indigenous clinics. To be eligible, clinics must serve lowerincome patients, agree to allow their physicians, Registered Dietitians and/or nurses to dispense healthy food prescriptions, appoint a staff member to liaise with the Implementation Support Team, and be willing to receive training. The final list of study sites, currently projected at 30 clinics, will be available in the clinicaltrials.gov registry.

\section{Participants}

PCCs will use information from electronic medical records to identify patients with T2DM and persistent hyperglycemia (i.e. A1C 8-12\%), including patients living in rural and urban areas, and those who identify as Indigenous. Potentially eligible patients will be invited to complete a brief screening questionnaire, including the validated two-item hunger vital sign, which is $97 \%$ sensitive and $83 \%$ specific for food insecurity [77-79]. Eligible patients will be adults (18-85 years) with persistent hyperglycemia (i.e. A1C 8-12\%) who are experiencing food insecurity, who are not currently on intensive insulin therapy (multiple daily injections or continuous subcutaneous insulin infusion), do not reside in a facility that provides meals (e.g. shelter, long term care, prison), and can communicate in English or have someone to translatePatients will be excluded if they have an A1C $<8 \%$ or $>12 \%$ (given the recommendation for anti-hyperglycemic treatment escalation for those with $\mathrm{A} 1 \mathrm{C}>12 \%$ ), have signs/symptoms of metabolic decompensation, have an eating disorder, are functionally dependent, have limited life expectancy (< 2 years), have experienced diabetic ketoacidosis or a hyperglycemic hyperosmolar emergency in the past 2 years, have a history of recurrent severe hypoglycemia or hypoglycemic unawareness, or if they have been diagnosed with dementia. Patients will also be excluded if they are pregnant or trying to conceive, breastfeeding, participating in other clinical trials, if someone in their household is currently or has previously participated, if they will no longer reside within $100 \mathrm{~km}$ of a participating supermarket in the next 6 months, if they plan to leave Canada for more than 2 weeks in the next 6 months, or if they will not be able to complete data collection at 6 months (e.g. due to moving).

Eligible patients will be asked to provide consent to their healthcare provider to be contacted by the research team. A Research Assistant will contact patients to confirm all eligibility criteria have been met, obtain informed consent and provide instructions for collection of baseline data. Participants may elect to report baseline patientreported data immediately over the telephone, or independently via the study's online data collection platforms. Any patients identified as food insecure at screening using the two-item hunger vital sign, but who do not respond affirmatively to any of the items on the full 18-item Household Food Security Survey Module during baseline data collection will be excluded. Participants will have biochemical and physical measurements performed at a community laboratory or at their PCC. Participants with an A1C outside the 8-12\% range will be excluded at that point. All participants will subsequently receive a healthy food prescription pamphlet from their healthcare provider (i.e. physician, nurse, Registered Dietitian) and a brief, high-level overview of its contents using standardized teaching guidelines, either virtually or in-person during a clinic visit. 


\section{Sample size calculation}

Based on local administrative data, we expect a mean baseline $\mathrm{A} 1 \mathrm{C}$ of $9.1 \%(\mathrm{SD}=1.0 \%$ ) in our sample (i.e. individuals with A1C 8-12\%) [80]. Assuming 5\% type I error, 35\% attrition [81] and potential design effects based on sampling in different clinics (25\% inflation), 403 participants are required for $95 \%$ power to detect a difference in $\mathrm{A} 1 \mathrm{C}$ of $0.5 \%$, which is often considered a minimally important clinical difference [17].

\section{Randomization and blinding}

Following baseline data collection and delivery of the healthy food prescription pamphlet, participants will be randomized to a subsidized healthy food prescription intervention $(n=202)$ or a healthy food prescription comparison group $(n=202)$ with a 1:1 allocation ratio using a computer-generated, concealed, blocked randomization sequence created by an independent statistician. Blocking variables will include gender, clinic type location (urban, rural, Indigenous) and baseline A1C (8-9\%, 9-12\%). Allocation concealment will be ensured via secure storage of the randomization sequence separately from the participant database, which will only be accessible by the statistician. To ensure researcher blinding, randomization will be operationalized via REDCap (Research Electronic Data Capture) following completion of baseline data collection. Intervention assignment will be communicated by Research Assistants via a telephone call. Participants cannot be blinded to treatment allocation, however details of the healthy food subsidy, including its monetary value and the types of foods that are eligible, will not be divulged to participants in the comparison group. Care providers and individuals who collect biochemical and physical measurements will be blinded to group allocation.

\section{Intervention}

Development of the subsidized healthy food prescription program was informed by the social prescribing literature, EQUIP (Research to Equip Primary Healthcare for Equity) principles of equity-oriented healthcare [82], initiatives elsewhere (e.g. Wholesome Wave [83]), and stakeholder consultation. The comparison group will receive a one-time healthy food prescription pamphlet. The intervention group will receive a one-time healthy food prescription pamphlet and a 6 month subsidy of $\$ 1.50 /$ day/household member (e.g. household of four receives $\$ 42 /$ week) to purchase healthy foods in study-affiliated supermarkets. Thus, the study is designed to test the impact of a healthy food subsidy, which is an intervention that targets economic rather than knowledge-related barriers to healthy eating. Aside from labelling the nutritional advice delivered as a "prescription" (which may have some independent impact on participants' behaviour), the healthy food prescription closely mimics current care (i.e. nutrition counselling) and is unlikely to substantially change dietary intake in the context of severe economic constraints [84-89]. The subsidy amount exceeds the benefit provided by similar US programs (e.g. [56, 83]) in order to more closely bridge the gap in food spending between food secure and insecure households in Canada [90]. In their systematic review, Rao et al (2013) demonstrated that a subsidy of $\$ 1.50 /$ day was associated with greater compliance with a Mediterranean style dietary pattern. The subsidy amount that each household receives will be determined based on household size at baseline; this amount will remain consistent throughout the intervention regardless of changes in household size. A household member is defined as a partner or a dependent child or adult who resides at the same location at least $50 \%$ of the time. Finally, the intervention will be delivered over 6 months to allow sufficient time for dietary changes to be reflected in approximately two A1C cycles [91]. 
The healthy food prescription pamphlet was designed by Registered Dietitians and modelled after a previous food prescription program to be a visually appealing, low literacy resource [92] (Additional File 5). The cover page contains the following pre-printed prescription "I prescribe a healthy eating pattern of minimally processed foods that have little to no added fat, sugar or salt," with space for the care provider to add their signature, date, and patient information. The inner pages outline an evidence-based healthy dietary pattern, with key messages to consume a variety of whole, minimally processed foods from all food groups with little to no added fat, sugar or salt, to spread carbohydrate foods over the day, to satisfy thirst with water, and to avoid sugary drinks, refined grains, sweets, confectionary and desserts [7, 93]. A diabetes-appropriate recipe is provided along with links to connect patients with sources of free/lower-cost food, additional recipes, nutrition information, other helpful community services and sources of emergency food assistance. Feedback from PCC staff and patients and the Advisory Boards was incorporated into the final version of the pamphlet.

The healthy food subsidy can be used to purchase whole, minimally processed foods with little to no added fat, sugar or salt from all food groups [7, 93] (Table 2). Ineligible items include beverages (except white milk), refined grains, sweets and other foods with excess fat, sugar or salt. A pilot-tested PDF booklet was created with pictures of eligible items to assist participants to locate eligible items and Research Assistants will review the list of subsidized foods and subsidy redemption procedures with participants prior to the intervention. Participants in the intervention group can redeem their food subsidies at participating supermarkets located throughout Alberta. Subsidies will be loaded onto participants' store loyalty card weekly, and dollars-off discounts will be automatically applied on subsidy-eligible foods at the point-of-purchase. The entire food subsidy must be spent during a single shop, either in-person or using a pick-up service. Subsidies not redeemed within the week will expire. To minimize potentially stigmatizing experiences, all participants in the intervention group will receive a one-time unrestricted grocery gift card valued at $\$ 30$. The grocery gift card can be used in the event that participants inadvertently exceed their subsidy amount and lack funds to cover the additional costs. Participants will also have access to a study email and telephone help-line where they can ask study-related questions. 
Table 2

Foods that qualify for the healthy food subsidy

\begin{tabular}{|c|c|}
\hline Food group & Eligible items \\
\hline \multirow[t]{3}{*}{ Vegetables and fruits } & Fresh vegetables and fruit \\
\hline & Frozen vegetables and fruit \\
\hline & Canned vegetables \\
\hline \multirow[t]{2}{*}{ Meat, poultry and fish } & Fresh meat, poultry and fish \\
\hline & Canned fish \\
\hline \multirow[t]{3}{*}{ Meat alternatives } & Dried or canned lentils, chickpeas or beans \\
\hline & Whole eggs \\
\hline & Whole almonds \\
\hline \multirow[t]{4}{*}{ Dairy products } & White cow's milk \\
\hline & Unsweetened fortified soy beverage \\
\hline & Plain yogurt \\
\hline & Hard cheddar cheese \\
\hline \multirow[t]{5}{*}{ Whole grain foods } & Whole grain pasta \\
\hline & Brown rice \\
\hline & Large flake rolled oats \\
\hline & $100 \%$ whole wheat bread \\
\hline & Bran Flakes cereal \\
\hline
\end{tabular}

\section{Data collection}

To support retention, all participants (regardless of treatment allocation) will receive $\$ 100$ following completion of data collection at baseline (0 months) and again at follow-up (6 months).

\section{Questionnaires}

Electronic questionnaires will encompass sociodemographic and health-related items, dietary intake in the previous 24 hours, and a variety of patient-reported outcomes. The final questionnaires will be reviewed by the Advisory Boards and Scientific Steering Committee to establish face and content validity, and will be pre-tested with patients.

Sociodemographic and health-related variables will be recorded in REDCap using existing items from the Canadian Community Health Survey where available [94], including date of birth, sex at birth, gender identity, race/ethnicity, years lived in Canada, household size and composition, number of household members with 
T2DM, educational attainment, employment status, marital status, annual household income, main income source, access to extended health benefits, participation in income support programs, smoking status, housing status, medication/insulin type and dose, duration of diabetes and physical activity level [95].

Patient-reported outcomes will be assessed using the following validated scales: World Health Organization wellbeing scale [96], Stanford Diabetes Self-Efficacy Scale [97, 98], Diabetes Self-Management Questionnaire [99, 100], Problem Areas in Diabetes Scale-5 to assess diabetes distress [101], EQ-5D-5L to assess self-rated health [102], hypoglycemic episodes [30], Work Productivity and Activity Impairment Questionnaire [103], Health Canada's Household Food Security Survey Module to assess experiences of marginal, moderate and severe household food insecurity in the past 6 months [104-106] and medication adherence [107]. We will also assess diabetes competing demands [108] and perceived financial barriers to chronic disease care, the latter of which has undergone testing via focus groups and cognitive interviews [109]. Subjective social status will be assessed using the MacArthur Scale of Subjective Social Status national and community ladders [110, 111]. Participants will report perceived income adequacy by answering the question: "Thinking about your total monthly income, how difficult or easy is it for you to make ends meet?" [112-114].

Quality of dietary intake will be assessed using the online Automated Self-Administered 24-hour Dietary Recall for Canada (ASA24-Canada-2018) whereby all participants will report all foods and beverages consumed from midnight to midnight the previous day, including location of consumption and dietary supplements [115-117]. The ASA24 has demonstrated good correspondence with standardized interviewer administered dietary recalls and with true intakes $[116,118]$. Participants will receive an unannounced email/text 2-4 days later prompting them to complete a second dietary recall to provide a more precise estimate of usual intake [119]. Dietary intake data will be used to calculate a Healthy Eating Index-2015 score from 0-100 for each participant, which provides a valid assessment of overall diet quality consistent with recommendations in the healthy food prescription pamphlet $[120,121]$.

To reduce missing data, REDCap will be configured to require a response prior to proceeding to the next question, although 'don't know' and 'refuse to answer' will be response options. Research Assistants will also review all completed questionnaires and will telephone participants within 24 hours to request responses to any unanswered questions.

\section{Clinical measurements}

Biochemical measurements will include quantification of blood glucose levels via A1C (standardized to the Diabetes Complications and Control Trial [122-125]) and fructosamine, as A1C can be unreliable for some patients and fructosamine is more sensitive to acute changes [126]. Blood lipids (total-, HDL- and LDL-cholesterol, triglycerides, apolipoprotein B), serum creatinine (to calculate estimated glomerular filtration rate), albumin-tocreatinine ratio and hemoglobin concentration will also be quantified. Participants will provide a urine sample to detect albuminuria. All samples will be analyzed by Alberta Precision Laboratories and DynaLIFE Medical Labs.

Physical measurements will adhere to standardized measurement protocols and will be performed a minimum of two times by trained researchers/clinicians, including weight and height to calculate BMI, waist circumference, systolic and diastolic blood pressure (using oscillometric devices approved by Hypertension Canada) and heart 
rate. Skin carotenoids will be assessed using Pharmanex Biophotonic Scanners as biomarkers of fruit and vegetable intake [127].

\section{Administrative health data}

A1C levels and information on comorbidities and diabetes complications will be obtained from Alberta Health Services' Analytics, Data Integration, Measurement and Reporting database. The secondary outcome of need for diabetes medication/insulin will be quantified by monitoring changes in medication/insulin use (i.e. initiation or discontinuation), type (i.e. Metformin, Sulfonylureas, Repaglinide, DPP-4 inhibitors, GLP1 receptor agonists, SGLT2-inhibitors, Acarbose, Thiazolidinediones, Statins or other lipid-lowering agents, Renin-angiotensin aldosterone antagonists and other anti-hypertensive agents) and dosage recorded in the Pharmaceutical Information Network Database [128]. We will also collect administrative data on health events and healthcare use on an ongoing basis post-intervention to support understanding of longer-term outcomes.

\section{Implementation fidelity}

Implementation fidelity will be continuously assessed using a combination of quantitative and qualitative measures as part of the implementation study (described below).

\section{Data monitoring and adverse events}

We have not established stopping guidelines or a data monitoring committee as the intervention is low-risk. In addition, physicians will be free to adjust patients' medication regimens to achieve improved glycemia, although they will be asked to initiate or uptitrate insulin therapy only when absolutely necessary. Given that serious adverse events are unlikely, adverse events will not be monitored and no provisions have been made for compensation. Interim analyses will not be conducted. At the conclusion of the study, participants will continue to be followed by their care providers.

\section{Data analysis}

Mixed-effects linear and multinomial logistic/ordinal regression will assess group differences in outcomes at follow-up, adjusted for baseline values of each outcome, blocking variables and covariates (specific to each outcome), with subgroup analyses by gender, rural and Indigenous status, baseline A1C (8-9\%, 9-12\%) and insulin use. Participant- and PCC-specific variations will be modeled using random effects. A dose-response analysis will examine whether outcomes depend on the value of food subsidies redeemed. Missing data will be handled using full information maximum likelihood under a missing at random assumption. Analyses will be intention-to-treat using all available data.

For the primary outcome of blood glucose levels, covariates will include the following: age, gender, race/ethnicity, educational attainment, years lived in Canada, number of children living in the home, marital status, change in number of household members since baseline, access to extended health benefits, participation in other income support programs, diabetes duration, and physical activity level. 


\section{Sensitivity analyses}

Sensitivity analyses will examine outcomes among patients whose diabetes medication/insulin regimen was unchanged during the 3 months prior to the study, throughout the study period, and when patients taking insulin are excluded. We will also examine the impact of excluding patients who were started on lipid-lowering or antihypertensive therapy from models assessing impact on blood lipids and blood pressure, respectively. Additional sensitivity analyses will consider the impact on findings when food insecurity is modelled as a continuous, rather than as a categorical outcome [129], and when an indicator of energy intake misreporting (i.e. the ratio of reported energy intake to estimated energy expenditure) is included in models assessing impact on diet quality.

We will also consider the impact on findings when models are adjusted for changes in medication/insulin type and dosage that occurred between baseline and follow-up. We propose to use a novel scoring system that attempts to match the changes made with the expected clinical impact on A1C [130]. The following changes will be assigned 1 point (expected change in A1C of 0.5\%): less than full dose of Metformin ( $2000 \mathrm{mg} /$ day), Sulfonylureas (Gliclazide < 60mg/day, Glyburide < 10mg/day), or Repaglinide (<5mg/day); any dose of DPP-4 inhibitor, SGLT2-inhibitor or Acarbose; initiation of basal insulin or insulin adjustment by $<20 \%$ of total daily dose. Two points (expected change in A1C of 1\%) will be assigned for: full dose of Metformin, Sulfonylureas or Repaglinide; any dose of GLP1 receptor agonists or Thiazolidinedione; initiation of bolus insulin or insulin adjustment of $>20 \%$ of total daily dose. Points will be attributed cumulatively for all medication/insulin changes. Addition of medication/insulin will be scored positively and reductions scored negatively to arrive at a final cumulative medication/insulin adjustment score for each participant.

Markov chain Monte Carlo multiple imputation, inverse probability weighting and available case analysis will be used to investigate the impact of different assumptions about missing data on estimated program impacts [131133]. Pattern mixture methods models [134] will be used to explore the robustness of study findings to the assumption that data were missing not at random [135].

\section{Implementation study}

\section{Study design and objectives}

A mixed methods implementation study will evaluate the RE-AIM $[65,66]$ of the subsidized healthy food prescription program, including contextual influences, patients' experiences in the program and perceived outcomes, reasons behind program successes and failures, implementation fidelity, mechanisms of impact and the likelihood of sustainability (Table 3). The Consolidated Framework for Implementation Research (CFIR) consolidates determinants of effective implementation into five domains (intervention characteristics, inner setting, outer setting, characteristics of individuals, implementation process), and will accordingly structure our investigation of determinants of effective implementation, including barriers and facilitators, within RE-AIM's implementation domain [136]. 
Table 3

Logic model for the implementation of a subsidized healthy food prescription program

\begin{tabular}{|c|c|c|c|c|c|}
\hline Inputs & Activities & Outputs & $\begin{array}{l}\text { Short-term } \\
\text { outcomes }\end{array}$ & $\begin{array}{l}\text { Longer-term } \\
\text { outcomes }\end{array}$ & Impact \\
\hline $\begin{array}{l}\text { Patient- } \\
\text { oriented } \\
\text { research, with } \\
\text { patients as } \\
\text { partners } \\
\text { · A type } 2 \\
\text { hybrid } \\
\text { effectiveness- } \\
\text { implementation } \\
\text { study design } \\
\text {. Scientific } \\
\text { Committee, } \\
\text { Advisory } \\
\text { Boards, and } \\
\text { PCC } \\
\text { Subcommittee } \\
\text {. PCC support } \\
\text { and } \\
\text { infrastructure } \\
\text {. } \\
\text { Organizational } \\
\text { champions } \\
\text { Funding and } \\
\text { in-kind support } \\
\text { from Alberta } \\
\text { Innovates, } \\
\text { Alberta Blue } \\
\text { Cross, Alberta } \\
\text { Health Services } \\
\text { and Nu-Skin } \\
\text { Implementation } \\
\text { Support Team } \\
\text {. Technical } \\
\text { support } \\
\text { imd }\end{array}$ & $\begin{array}{l}\text { partnership } \\
\text { agreements } \\
\text { · Readiness, } \\
\text { capacity, } \\
\text { barriers/facilitators } \\
\text { and } \\
\text { implementation } \\
\text { assessments } \\
\text {. Co- } \\
\text { customization of } \\
\text { care pathways and } \\
\text { implementation } \\
\text { strategies } \\
\text {. Education and } \\
\text { training, including } \\
\text { booster training } \\
\text { Ongoing } \\
\text { monitoring and } \\
\text { evaluation } \\
\text {. Regular } \\
\text { communication, } \\
\text { including } \\
\text { continuous } \\
\text { implementation } \\
\text { feedback }\end{array}$ & $\begin{array}{l}\cdot \text { \# and \% of } \\
\text { subsidies } \\
\text { redeemed } \\
\cdot \quad \text { \# and \% of } \\
\text { subsidies } \\
\text { redeemed for } \\
\text { eligible/ineligible } \\
\text { items } \\
\text { · \# and type of } \\
\text { PCCs and care } \\
\text { providers that } \\
\text { participate } \\
\text { · \# and \% of } \\
\text { staff who } \\
\text { participate in } \\
\text { training } \\
\text { · \# and \% of } \\
\text { patients who } \\
\text { participate } \\
\text {. Patient } \\
\text { experiences } \\
\text { Implementation } \\
\text { fidelity } \\
\text {. Cost- } \\
\text { effectiveness } \\
\text { analysis }\end{array}$ & $\begin{array}{l}\text { S Successful } \\
\text { integration of } \\
\text { care } \\
\text { pathways } \\
\text { within PCC } \\
\text { workflows } \\
\text { · Increased } \\
\text { awareness of } \\
\text { effective } \\
\text { strategies to } \\
\text { reduce food } \\
\text { insecurity } \\
\text { - Increased } \\
\text { empowerment } \\
\text { for patients } \\
\text { and care } \\
\text { providers } \\
\text { - Increased } \\
\text { care provider } \\
\text { motivation to } \\
\text { sustain care } \\
\text { pathways } \\
\text { Improved } \\
\text { diet quality } \\
\text {. Reduced } \\
\text { food } \\
\text { insecurity } \\
\text { - Improved } \\
\text { diabetes } \\
\text { management }\end{array}$ & $\begin{array}{l}\text {. Improved } \\
\text { quality of care } \\
\text { · Improved } \\
\text { patient } \\
\text { satisfaction } \\
\text { · Improved } \\
\text { glycemia } \\
\text { · Reduced } \\
\text { chronic } \\
\text { diabetes } \\
\text { complications } \\
\text { - } \\
\text { Commitments } \\
\text { from Alberta } \\
\text { Health } \\
\text { Services, } \\
\text { PCCs, Alberta } \\
\text { Blue Cross } \\
\text { and } \\
\text { supermarkets } \\
\text { to collaborate } \\
\text { for longer-term } \\
\text { sustainability }\end{array}$ & $\begin{array}{l}\text { Decreased } \\
\text { acute care } \\
\text { usage } \\
\text { Decreased } \\
\text { acute care } \\
\text { costs }\end{array}$ \\
\hline
\end{tabular}

PCC: Primary care clinic

GOAL: To support adults who are experiencing food insecurity and persistent hyperglycemia to manage their diabetes with a healthy diet.

SITUATION: In Alberta, more than 54,000 adults are experiencing food insecurity and type 2 diabetes, including 13,600 Indigenous individuals who bear a disproportionately high burden [166-169] This group of Albertans incurs $\$ 842$ million/year in healthcare costs, with a small subset of 9,600 individuals with persistent hyperglycemia incurring nearly one-quarter of these costs $[20,24,165,166,170]$. Nevertheless, although it is well known that food insecurity is a primary driver of acute care usage and costs, primary care providers often lack effective strategies to address it.

\section{Implementation process}


The implementation process will unfold according to the four phases and action-oriented steps in the Quality Implementation Framework (QIF) [137, 138].

\section{QIF phase 1: Initial considerations regarding the host setting}

1. Stakeholder buy-in: Partnership agreements will be finalized with all stakeholders.

2. Implementation Support Team: An Implementation Support Team will be formed to administer, plan, support, monitor and evaluate implementation of the intervention.

3. Training: Study personnel will be trained in principles of equity-oriented care $[82,139,140]$ and study procedures.

4. Assess needs, fit, capacity, readiness and adaptations: Implementation strategies will be tailored by clinic using a theory-informed modified conjoint analysis [141] in which PCC staff will complete a questionnaire to identify potential implementation barriers and facilitators within the five domains of CFIR. Researchers will use the CFIR-ERIC (Expert Recommendations for Implementing Change compilation) matching tool to identify strategies to mitigate the barriers and leverage the facilitators identified by each clinic [136, 141-145].

5. Pre-Implementation planning and adaptations: The Implementation Support Team will develop a preimplementation plan and timeline and will execute it, including co-developing infrastructural supports, training modules, and care pathways with PCC staff and patients. The Indigenous Advisory Board will progress relationship building with Indigenous PCCs and will work with them to adapt infrastructural supports and care pathways as required.

6. Capacity building and supportive organizational climate: PCC staff will be trained in principles of equityoriented care $[82,139,140]$ and study procedures. Training sessions and co-design processes will enhance buy-in and readiness to change. One staff designate per organization will liaise with the Implementation Support Team weekly and will serve as an organizational champion.

7. Study planning: The Implementation Support Team will develop study protocols and procure materials for all three studies.

\section{QIF phase 2: Creating a structure for implementation}

1. Implementation planning and adaptations: The Implementation Support Team will use findings from the modified conjoint analysis to develop a detailed implementation plan and timeline, co-customize it with PCCs, and assign specific roles and responsibilities. Subsidy redemption procedures will be finalized.

\section{QIF phase 3: Implementation and ongoing implementation structure}

1. Program implementation and data collection: The subsidized healthy food prescription program will be implemented and data collection for the RCT and modelling study will proceed (Figure 2).

2. Technical support and communication: The Implementation Support Team will provide ongoing support to PCC staff, including via weekly meetings with staff designates. Booster training sessions will be held when new/modified processes are introduced and for new staff. 
3. Implementation study and feedback mechanisms: The Implementation Support Team will collect data continuously for the implementation study. Ongoing monitoring and provision of feedback to PCCs will support continuous quality improvement.

\section{QIF phase 4: Improving future applications}

1. Data analysis: The research team will analyse and integrate data from all three studies.

2. Knowledge translation and learning from experience: The research team and Advisory Boards will jointly interpret and disseminate findings. Outcomes from a deliberative dialogue $[146,147]$ knowledge translation event will inform sustainability planning.

\section{Data collection}

Implementation processes and outcomes related to all five RE-AIM domains, and determinants of effective implementation within CFIR domains, will be repeatedly measured via quantitative and qualitative data collected by trained Research Assistants. Participants will receive $\$ 30$ for participating in interviews and $\$ 5$ for completing questionnaires.

\section{Quantitative data}

Quantitative data will be collected via administrative records of the numbers and characteristics of PCCs and patients that do and do not participate (reach and adoption), the number and types of healthcare providers who receive training (implementation), healthy food prescription and subsidy allocation data (implementation), audits of supermarket subsidy transaction data (implementation), and implementation fidelity checklists completed by patients (implementation). Quantitative data will also encompass the aforementioned questionnaire pertaining to barriers/facilitators completed as part of the modified conjoint analysis. A post-intervention questionnaire will be distributed to PCC staff and patients to explore all five RE-AIM domains, including barriers/facilitators.

\section{Qualitative data}

Qualitative data pertaining to program effectiveness, implementation (including barriers and facilitators) and maintenance will be continuously collected via weekly meetings with PCC staff liaisons and through interviews with patients. The latter will entail post-intervention semi-structured interviews with 30 purposively selected patients to understand their overall experience of participating in the program, including fidelity of intervention delivery, barriers/facilitators, and how the program influenced the medical management of their T2DM. An additional 30 patients will be recruited to participate in longitudinal (pre- and post-subsidy), shop-along, think aloud qualitative interviews to understand the experience of redeeming food subsidies and how they influenced patients' food purchasing patterns. We will also record and collect qualitative observations of Indigenous Advisory Board meetings and interview Board members to understand how the program unfolded from their perspective. 


\section{Implementation fidelity}

From the measures summarized above, objective measures of implementation fidelity will include subsidy allocation data and audits of supermarket subsidy transaction data. Perceived measures of implementation fidelity will be reported by patients via quantitative checklists and semi-structured interviews.

\section{Data analysis}

\section{Quantitative data}

Quantitative findings pertaining to all five RE-AIM domains will be summarized using descriptive statistics and will inform areas for subsequent in-depth qualitative exploration. We will stratify our analyses by clinic type (urban, rural, Indigenous) to examine any meaningful differences between them.

\section{Qualitative data}

Qualitative data will be coded by two trained researchers using directed content analysis [148], whereby development of an initial coding scheme for each set of interviews will be informed by RE-AIM, CFIR and other frameworks as appropriate. Concurrent data collection and analysis and regular meetings between researchers will permit iterative adjustments to the interview questions and coding schemes, and continuous evaluation of the adequacy of the samples [149]. Sampling will end when new concepts are no longer being identified in the data.

\section{Data integration}

Quantitative and qualitative data will be integrated during the analysis stage for the purposes of expansion (e.g. qualitative data will help to elaborate and explain quantitative findings) and convergence (e.g. to examine whether quantitative and qualitative fidelity ratings correspond) [150].

\section{Modelling study}

\section{Study design and objectives}

A modelling study will estimate longer-term effectiveness of the subsidized healthy food prescription program on diabetes-related complications, resource use and costs.

\section{Data collection}

The individual-level data required as inputs for the model will be captured in the baseline and follow-up assessment phase of the RCT, as previously described. Model inputs required to estimate program impact on longer-term resource use and costs will be obtained from Alberta Health Services' Analytics, Data Integration, 
Measurement and Reporting database, including emergency department, inpatient, specialist, general practice and urgent care costs. The costs of the intervention will include administrative costs associated with implementing the program and the costs of food subsidies at a household level. The time to administer the program will be based on the non-research hours of the study personnel and unit costs will be obtained from the Alberta Wage and Salary Survey [151].

\section{Data analysis}

The potential longer-term health and economic impacts of the subsidized healthy food prescription program will be modelled using the validated UK Prospective Diabetes Study outcomes simulation model-2 [152]. Healthrelated model outputs will include differences between the intervention and comparison groups in cardiovascular events, amputation, blindness, renal failure, diabetic foot ulcers, and mortality over 1 year, 5 year and lifetime scenarios. Model outputs related to the economic impacts of the intervention will include the incremental difference in costs and quality adjusted life years [153] between the intervention and comparison groups, the incremental cost-effectiveness ratio and the net benefit. A budget impact analysis will explore the difference in costs (e.g. prescriptions, physician visits, hospitalizations) considering the RE-AIM domains, and return on investment from the public payer perspective over 1 year, 5 year and lifetime scenarios.

\section{Data integration and dissemination}

Data from each of the three studies will be published separately, with an additional final publication that will integrate and synthesize findings for all RE-AIM domains to examine the following specific outcomes:

Reach will be assessed by calculating the: a) absolute number and proportion of adults who are experiencing food insecurity and persistent hyperglycemia In Alberta who participate; b) absolute number and proportion of individuals experiencing household food insecurity who are potentially reached by the intervention (by virtue of living in the household of a participant); c) absolute number and proportion of eligible adults who are invited who participate (i.e. participation rate).

Effectiveness will be assessed via: a) impact on primary and secondary outcomes; b) perceived positive and negative program experiences, mechanisms of impact and outcomes reported by PCC staff and patients; and c) impact on longer-term health outcomes, resource use and costs.

Adoption will be assessed by calculating the: a) absolute number and proportion of PCCs that participate, and their representativeness; b) absolute number and proportion of care providers who participate, and their representativeness; and c) reasons why PCCs and care providers decline to participate.

Implementation will be assessed by determining: a) the absolute number, type and proportion of care providers who receive training; $b$ ) the number of healthy food prescriptions prescribed; $c$ ) the value of food subsidies allocated; $d$ ) the proportion and value of food subsidies redeemed (i.e. dose); e) implementation fidelity; f) PCC staff and patient-reported barriers, facilitators and contextual influences on program implementation and uptake; and g) PCC staff and patient-perceived quality of infrastructural supports. 
Maintenance will be assessed via: a) PCC staff-reported longer-term program feasibility, acceptability, organizational fit and willingness to deliver it; b) patient-reported longer-term program acceptability and willingness to participate; c) evidence of successful program integration within PCC and supermarket workflows; d) how aspects of the program are sustained or change over time; e) PCC staff and patient suggestions for program improvement; f) reasons for drop-out; and g) commitments from study partners, including Alberta Health Services, PCCs, Alberta Blue Cross and participating supermarkets to collaborate on research to assess program scale-up and longer-term sustainability.

These fully integrated data will be disseminated via technical reports, lay summaries, infographics, policy briefs, academic publications and oral/poster presentations.

\section{Discussion}

Adults who are experiencing food insecurity cannot consume the healthy foods they require to manage their diabetes if they lack sufficient funds to purchase them. However, primary care providers often lack access to resources that could assist them to alleviate their patients' experiences of food insecurity. By addressing incomerelated causes of unhealthy dietary patterns and persistent hyperglycemia, subsidized healthy food prescription programs can equip clinicians with resources that assist their patients to maintain a healthier dietary pattern. Over the longer-term, maintenance of a healthier dietary pattern can improve health and reduce diabetes-related healthcare expenditures $[7-15,61]$.

We will investigate the RE-AIM of a subsidized healthy food prescription program for adults who are experiencing food insecurity and persistent hyperglycemia. Through a RCT, modelling and implementation studies, we will generate comprehensive, in-depth and robust data pertaining to the short- and longer-term impacts of the program on glycemia, other health-related outcomes, resource use and costs, while also providing valuable implementation data to support translation of research findings into practice and policy. Integration of findings from these three studies acknowledges the reality that although evidence of short-term effectiveness from RCTs is valuable, such data are on their own insufficient to promote widespread and high quality implementation. In this respect, the implementation study will be critical to unpack reasons underlying the program's successes and failures, mechanisms of impact, determinants of effective implementation, and the likelihood of sustainability. Notably, our findings will be immediately relevant to existing programs such as Wholesome Wave, which has been providing fruit and vegetable prescriptions to US households since 2010 [83], and can inform more specific recommendations regarding strategies to address food insecurity in patients with diabetes [10, 154]. Moreover, opening up conversations around food insecurity may also provide a gateway to address other social determinants of health that constrain patients' health potential.

\section{Potential risks and limitations}

Our literature review $[43,58,70-72,92,155-161]$ and stakeholder engagement identified several potential study risks. First, a single implementation model may not be effective for all PCCs, which could adversely affect implementation fidelity. We will therefore use a modified conjoint analysis to select PCC-specific implementation strategies, co-customize and pilot test care pathways with PCCs to ensure compatibility, and monitor implementation fidelity. We will also provide comprehensive training with booster sessions, continuous technical support, and will meet weekly with staff designates and promptly address any concerns. Ongoing engagement, 
the support of operational leaders within the healthcare system and over-recruitment of PCCs will help to mitigate against and accommodate drop-out, should it occur. Primary risks at the patient level include failure to redeem subsidies or drop-out. To mitigate against these risks, participants will receive email reminders to redeem their food subsidies and will have access to a study help-line for support. Moreover, both groups will receive $\$ 100$ at baseline and follow-up as compensation, which will also serve as a recruitment incentive.

Participants' anti-hyperglycemic regimen may be intensified by their care provider during the observation period, which can exert a significant impact on A1C. The tendency to intensification and deintensification should be balanced between groups owing to randomization, nevertheless, we will monitor medication/insulin type/dosage for use as adjustment variables in sensitivity analyses. In addition, need for diabetes medication/insulin has been included as a secondary outcome, whereby deintensification will be considered a positive, and intensification a negative outcome.

\section{Conclusions}

Subsidized healthy food prescription programs hold tremendous potential to improve health and reduce healthcare costs given that $20 \%$ of global morbidity and mortality is attributable to poor diet quality [162], and that food insecurity is a strong predictor of high-cost healthcare use $[26,163]$. In addition, the benefits of such programs extend to all household members, including children, for whom positive health outcomes may accrue across the lifecourse. In an era of unsustainable increases in healthcare costs, the healthcare system ignores the socioeconomic needs of patients at its peril [159]. Failure to effectively address food insecurity among adults with T2DM portends unsustainable escalations in healthcare usage and costs [29, 32, 36-38, 163-165]. We have proposed a comprehensive investigation of the RE-AIM of a subsidized healthy food prescription program. Ultimately, study findings will show whether a small upstream investment in a subsidized healthy food prescription program may avert substantially higher healthcare costs to treat diabetes complications after they emerge.

\section{Abbreviations}

A1C: glycosylated hemoglobin level; BMI: Body mass index; CFIR: Consolidated Framework for Implementation Research; EQUIP: Research to Equip Primary Healthcare for Equity; PCC: Primary care clinic; QIF: Quality Implementation Framework; RCT: Randomized controlled trial; RE-AIM: Reach, Effectiveness, Adoption, Implementation and Maintenance; REDCap: Research Electronic Data Capture; T2DM: Type 2 diabetes

\section{Declarations}

\section{Ethics approval and consent to participate}

This research has been approved by the University of Calgary Conjoint Health Research Ethics Board (REB200543) and the University of Alberta Health Research Ethics Board Biomedical Panel (Pro00107116). All participants will provide written, informed consent prior to data collection (Additional file 1).

\section{Consent for publication}




\section{Availability of data and materials}

The datasets analyzed in this study will be available from the corresponding author on reasonable request.

\section{Competing interests}

DLO and DJTC have received funding from a Petro-Canada Young Innovator Award in Community Health. The remaining authors declare that they have no competing interests.

\section{Funding}

This study is funded by a Partnership for Research and Innovation in the Health System 5 grant from Alberta Innovates (https://albertainnovates.ca/) and Alberta Health Services. Food subsidies are funded by Alberta Blue Cross, a not-for-profit supplemental health insurance provider. Nu Skin has provided in-kind support through the provision of skin carotenoid scanners. The study funders had no role in study design, in writing the report or in the decision to submit it for publication.

\section{Authors' contributions}

DLO and DJTC drafted the manuscript. All authors designed the study, edited, read and approved the final manuscript.

\section{Acknowledgements}

The authors would like to acknowledge the Registered Dietitians who developed the healthy eating prescription pamphlet: Laura White, Suzanne Galesloot, Stephanie Krug, Kaylee Chichak, Erin Montgomery-Fajic, Monika Glassford, and Kelly Berg.

\section{References}

1. American Diabetes A. Economic Costs of Diabetes in the U.S. in 2017. Diabetes care 2018; 41(5):917-928.

2. Health Care System Cost of People With Diabetes, 2013. [https://open.alberta.ca/dataset/a2a60d91-081e42c8-8d4a-466bb3506399/resource/34c90d83-caa3-4def-ab78-3a8987e2d7d7/download/phsb-03-2013diabetes-cost.pdf]

3. New diabetes rates released with urgent plea for governments to implement national diabetes strategy, 2019. [https://www.diabetes.ca/media-room/press-releases/new-diabetes-rates-released-with-urgent-plea-forgovernments-to-implement-national-diabetesstrategy\#: :text=Jan\%20Hux\%2C\%20President\%20and\%20CEO,under\%20\%2430\%20billion\%20this\%20year.] 
4. Quantitative Economic Decisions Inc: Canadian Diabetes Cost Model. The Canadian Diabetes Cost Model was developed for Diabetes Canada by Quantitative Economic Decisions, Inc. (formerly Informetrica Limited) and publicly released in 2009 . The forecasting model provides projections about the prevalence, incidence and economic burden of diabetes for Canadian society based on national surveillance data from the Canadian Chronic Disease Surveillance System. . In.; 2009.

5. O'Reilly DJ, Xie F, Pullenayegum E , et al. Estimation of the impact of diabetes-related complications on health utilities for patients with type 2 diabetes in Ontario, Canada. Qual Life Res 2011; 20(6):939-943.

6. Bradley C, Speight J. Patient perceptions of diabetes and diabetes therapy: assessing quality of life. Diabetes Metab Res Rev 2002; 18 Suppl 3:S64-69.

7. Diabetes Canada Clinical Practice Guidelines Expert C, Sievenpiper JL, Chan CB , et al. Nutrition Therapy. Canadian journal of diabetes 2018; 42 Suppl 1:S64-S79.

8. Evert AB, Dennison M, Gardner CD , et al. Nutrition Therapy for Adults With Diabetes or Prediabetes: A Consensus Report. Diabetes care 2019; 42(5):731-754.

9. Neuenschwander M, Ballon A, Weber KS , et al. Role of diet in type 2 diabetes incidence: umbrella review of meta-analyses of prospective observational studies. BMJ 2019; 366:I2368.

10. American Diabetes Association. Improving Care and Promoting Health in Populations: Standards of Medical Care in Diabetes-2019. Diabetes Care, 2019; 42(Suppl 1):S7-S12.

11. Stratton IM, Adler Al, Neil HA, et al. Association of glycaemia with macrovascular and microvascular complications of type 2 diabetes (UKPDS 35): prospective observational study. BMJ 2000; 321(7258):405412.

12. UK Prospective Diabetes Study (UKPDS) Group. Effect of intensive blood-glucose control with metformin on complications in overweight patients with type 2 diabetes (UKPDS 34). UK Prospective Diabetes Study (UKPDS) Group. Lancet 1998; 352(9131):854-865.

13. UK Prospective Diabetes Study (UKPDS) Group. Intensive blood-glucose control with sulphonylureas or insulin compared with conventional treatment and risk of complications in patients with type 2 diabetes (UKPDS 33). UK Prospective Diabetes Study (UKPDS) Group. Lancet 1998; 352(9131):837-853.

14. Zhu CH, Zhang SS, Kong $Y$, et al. Effects of intensive control of blood glucose and blood pressure on microvascular complications in patients with type II diabetes mellitus. Int J Ophthalmol 2013; 6(2):141-145.

15. Antonio JP, Sarmento RA, de Almeida JC. Diet Quality and Glycemic Control in Patients with Type 2 Diabetes. J Acad Nutr Diet 2019; 119(4):652-658.

16. Nathan DM, Kuenen J, Borg R, et al. Translating the A1C assay into estimated average glucose values. Diabetes care 2008; 31(8):1473-1478.

17. Little RR, Rohlfing CL, Sacks DB , et al. Status of hemoglobin A1c measurement and goals for improvement: from chaos to order for improving diabetes care. Clin Chem 2011; 57(2):205-214.

18. Rao M, Afshin A, Singh G, et al. Do healthier foods and diet patterns cost more than less healthy options? A systematic review and meta-analysis. BMJ open 2013; 3(12):e004277.

19. Canada's Food Price Report 10th edition 2020, 2020. [https://cdn.dal.ca/content/dam/dalhousie/pdf/sites/agrifood/Canada\%20Food\%20Price\%20Report\%20Eng\%202020.pdf] 
20. Campbell DJ, Ronksley PE, Hemmelgarn BR , et al. Association of enrolment in primary care networks with diabetes care and outcomes among First Nations and low-income Albertans. Open Med 2012; 6(4):e155-165.

21. McBrien KA, Manns BJ, Hemmelgarn BR , et al. The association between sociodemographic and clinical characteristics and poor glycaemic control: a longitudinal cohort study. Diabetic medicine : a journal of the British Diabetic Association 2016; 33(11):1499-1507.

22. Deved V, Jette N, Quan H, et al. Quality of care for First Nations and non-First Nations People with diabetes. Clin J Am Soc Nephrol 2013; 8(7):1188-1194.

23. Dyck RF, Sidhu N, Klomp H , et al. Differences in glycemic control and survival predict higher ESRD rates in diabetic First Nations adults. Clin Invest Med 2010; 33(6):E390-397.

24. McBrien KA, Manns BJ, Chui B , et al. Health care costs in people with diabetes and their association with glycemic control and kidney function. Diabetes care 2013; 36(5):1172-1180.

25. Household food insecurity by province and territory, 2014, 2014. [https://proof.utoronto.ca/food-insecurity/]

26. Fitzpatrick T, Rosella LC, Calzavara A, et al. Looking Beyond Income and Education: Socioeconomic Status Gradients Among Future High-Cost Users of Health Care. Am J Prev Med 2015; 49(2):161-171.

27. Mayer VL, McDonough K, Seligman H, et al. Food insecurity, coping strategies and glucose control in lowincome patients with diabetes. Public Health Nutr 2016; 19(6):1103-1111.

28. Berkowitz SA, Baggett TP, Wexler DJ , et al. Food insecurity and metabolic control among U.S. adults with diabetes. Diabetes care 2013; 36(10):3093-3099.

29. Seligman HK, Davis TC, Schillinger D, et al. Food insecurity is associated with hypoglycemia and poor diabetes self-management in a low-income sample with diabetes. J Health Care Poor Underserved 2010; 21(4):1227-1233.

30. Seligman HK, Jacobs EA, Lopez A, et al. Food insecurity and hypoglycemia among safety net patients with diabetes. Archives of internal medicine 2011; 171(13):1204-1206.

31. Berkowitz SA, Gao X, Tucker KL. Food-insecure dietary patterns are associated with poor longitudinal glycemic control in diabetes: results from the Boston Puerto Rican Health study. Diabetes care 2014; 37(9):2587-2592.

32. Berkowitz SA, Meigs JB, DeWalt D, et al. Material need insecurities, control of diabetes mellitus, and use of health care resources: results of the Measuring Economic Insecurity in Diabetes study. JAMA Intern Med $2015 ; 175(2): 257-265$.

33. Silverman J, Krieger J, Kiefer M , et al. The Relationship Between Food Insecurity and Depression, Diabetes Distress and Medication Adherence Among Low-Income Patients with Poorly-Controlled Diabetes. Journal of general internal medicine 2015; 30(10):1476-1480.

34. Heerman WJ, Wallston KA, Osborn CY, et al. Food insecurity is associated with diabetes self-care behaviours and glycaemic control. Diabetic Med 2016; 33(6):844-850.

35. Gucciardi E, Vahabi M, Norris N, et al. The Intersection between Food Insecurity and Diabetes: A Review. Curr Nutr Rep 2014; 3(4):324-332.

36. Nelson K, Cunningham W, Andersen R, et al. Is food insufficiency associated with health status and health care utilization among adults with diabetes? Journal of general internal medicine 2001; 16(6):404-411.

37. Seligman HK, Bolger AF, Guzman D , et al. Exhaustion of food budgets at month's end and hospital admissions for hypoglycemia. Health Aff (Millwood) 2014; 33(1):116-123.

Page 24/33 
38. Gucciardi E, Vogt JA, DeMelo M , et al. Exploration of the relationship between household food insecurity and diabetes in Canada. Diabetes care 2009; 32(12):2218-2224.

39. Diabetes Canada Clinical Practice Guidelines Expert C, Imran SA, Agarwal G, et al. Targets for Glycemic Control. Canadian journal of diabetes 2018; 42 Suppl 1:S42-S46.

40. Diabetes Incidence among First Nations in Alberta, 2017. [http://www.afnigc.ca/main/includes/media/pdf/fnhta/HTAFN-2017-04-04-Diabetes_Incidence.pdf]

41. The First Nations Regional Health Survey. Phase 3: Volume 2, 2018. [https://fnigc.ca/sites/default/files/docs/fnigc_rhs_phase_3_volume_two_en_final_screen.pdf]

42. Household food insecurity in Canada, 2017-2018, 2020. [https://proof.utoronto.ca/food-insecurity/]

43. Aiyer JN, Raber M, Bello RS, et al. A pilot food prescription program promotes produce intake and decreases food insecurity. Translational behavioral medicine 2019; 9(5):922-930.

44. Forbes JM, Forbes CR, Lehman E, et al. "Prevention Produce": Integrating Medical Student Mentorship into a Fruit and Vegetable Prescription Program for At-Risk Patients. Perm J 2019; 23.

45. Wetherill MS, Chancellor McIntosh H, Beachy C , et al. Design and Implementation of a Clinic-Based Food Pharmacy for Food Insecure, Uninsured Patients to Support Chronic Disease Self-Management. J Nutr Educ Behav 2018; 50(9):947-949.

46. Impacts of the fruit and vegetable prescription program, 2015. [https://www.wholesomewave.org/sites/default/files/wp-content/uploads/2016/02/BCBS_FVRxReport.pdf]

47. Ridberg RA, Bell JF, Merritt KE , et al. A Pediatric Fruit and Vegetable Prescription Program Increases Food Security in Low-Income Households. J Nutr Educ Behav 2019; 51(2):224-230 e221.

48. Trapl ES, Smith S, Joshi K, et al. Dietary Impact of Produce Prescriptions for Patients With Hypertension. Prev Chronic Dis 2018; 15:E138.

49. Cavanagh M, Jurkowski J, Bozlak C, et al. Veggie Rx: an outcome evaluation of a healthy food incentive programme. Public Health Nutr 2017; 20(14):2636-2641.

50. Wholesome Wave's fruit and vegetable prescription program, New York City 2013 outcomes, 2013. [https://www.wholesomewave.org/sites/default/files/wp-content/uploads/2014/10/FVRx2013_HHC_Report.pdf]

51. Wholesome Wave's fruit and vegetable prescription program, New York City 2014 outcomes, 2014. [https://www.wholesomewave.org/sites/default/files/wp-content/uploads/2014/10/FVRx2013_HHC_Report.pdf]

52. Wholesome Wave's Fruit and Vegetable Prescription Program 2013 Report, 2014.

[https://www.wholesomewave.org/sites/default/files/wp-content/uploads/2014/10/2013-FVRxReport_Final-1.pdf]

53. Wholesome Wave's Fruit and Vegetable Prescription Program 2012 Program Report, 2012. [https://www.wholesomewave.org/sites/default/files/wpcontent/uploads/2014/07/FVRx_2012Report_FINAL.pdf]

54. Black AP, Vally H, Morris $P$, et al. Nutritional impacts of a fruit and vegetable subsidy programme for disadvantaged Australian Aboriginal children. The British journal of nutrition 2013; 110(12):2309-2317.

55. Black AP, Vally H, Morris PS, et al. Health outcomes of a subsidised fruit and vegetable program for Aboriginal children in northern New South Wales. The Medical journal of Australia 2013; 199(1):46-50. 
56. Bryce R, Guajardo C, llarraza D , et al. Participation in a farmers' market fruit and vegetable prescription program at a federally qualified health center improves hemoglobin A1C in low income uncontrolled diabetics. Prev Med Rep 2017; 7:176-179.

57. Jones LJ, VanWassenhove-Paetzold J, Thomas K, et al. Impact of a Fruit and Vegetable Prescription Program on Health Outcomes and Behaviors in Young Navajo Children. Curr Dev Nutr 2020; 4(8):nzaa109.

58. Friedman DB, Freedman DA, Choi SK, et al. Provider communication and role modeling related to patients' perceptions and use of a federally qualified health center-based farmers' market. Health promotion practice 2014; 15(2):288-297.

59. Trapl ES, Joshi K, Taggart M , et al. Mixed methods evaluation of a produce prescription program for pregnant women. Journal of Hunger \& Environmental Nutrition 2017; 12(4):529-543.

60. Buyuktuncer Z, Kearney M, Ryan CL , et al. Fruit and vegetables on prescription: a brief intervention in primary care. Journal of human nutrition and dietetics : the official journal of the British Dietetic Association 2014; 27 Suppl 2:186-193.

61. Lee Y, Mozaffarian D, Sy S, et al. Cost-effectiveness of financial incentives for improving diet and health through Medicare and Medicaid: A microsimulation study. PLoS Med 2019; 16(3):e1002761.

62. Freedman DA, Choi SK, Hurley $T$, et al. A farmers' market at a federally qualified health center improves fruit and vegetable intake among low-income diabetics. Prev Med 2013; 56(5):288-292.

63. Zhou X, Zhang P. Response to Comment on Zhou et al. Cost-effectiveness of Diabetes Prevention Interventions Targeting High-risk Individuals and Whole Populations: A Systematic Review. Diabetes Care 2020;43:1593-1616. Diabetes care 2020; 43(12):e206-e207.

64. Curran GM, Bauer M, Mittman B , et al. Effectiveness-implementation hybrid designs: combining elements of clinical effectiveness and implementation research to enhance public health impact. Medical care 2012; 50(3):217-226.

65. Glasgow RE, Nelson CC, Strycker LA, et al. Using RE-AIM metrics to evaluate diabetes self-management support interventions. Am J Prev Med 2006; 30(1):67-73.

66. Glasgow RE, Vogt TM, Boles SM. Evaluating the public health impact of health promotion interventions: the RE-AIM framework. Am J Public Health 1999; 89(9):1322-1327.

67. The First Nations Principles of OCAP, 2019. [https://www.afn.ca/uploads/files/nihbforum/info_and_privacy_doc-ocap.pdf]

68. Tri-Council Policy Statement: Ethical Conduct for Research Involving Humans - TCPS 2 (2018), 2018. [http://www.pre.ethics.gc.ca/eng/policy-politique_tcps2-eptc2_2018.html]

69. Indigenous Health Transformational Roadmap 2018-2020, 2018.

[https://www.albertahealthservices.ca/assets/about/scn/ahs-scn-ppih-ih-roadmap.pdf]

70. Campbell DJ, Manns BJ, Hemmelgarn BR , et al. Understanding Financial Barriers to Care in Patients With Diabetes. The Diabetes educator 2017; 43(1):78-86.

71. Campbell DJ, Manns BJ, Leblanc $P$, et al. Finding resiliency in the face of financial barriers: Development of a conceptual framework for people with cardiovascular-related chronic disease. Medicine (Baltimore) 2016; 95(49):e5561.

72. Kulhawy-Wibe S, King-Shier KM, Barnabe C , et al. Exploring structural barriers to diabetes self-management in Alberta First Nations communities. Diabetol Metab Syndr 2018; 10:87. 
73. Campbell D, Campbell R, Larsen M , et al: Home Sweet Home(less): Giving diabetes a voice from the street Images and stories from a community-based photovoice project. In: North American Primary Care Research Group Annual Meeting. Toronto, ON; 2019.

74. Campbell D, Campbell R, Larsen M , et al: Creating together: Designing and conducting a community-based participatory research project. In: Canadian Alliance to End Homelessness Annual Meeting. Edmonton, AB; 2019.

75. Indigenous Food Sovereignty, [https://foodsecurecanada.org/resources-news/newsletters/1-indigenousfood-sovereignty]

76. Barnard LS, Wexler DJ, DeWalt D , et al. Material need support interventions for diabetes prevention and control: a systematic review. Curr Diab Rep 2015; 15(2):574.

77. Hager ER, Quigg AM, Black MM , et al. Development and validity of a 2-item screen to identify families at risk for food insecurity. Pediatrics 2010; 126(1):e26-32.

78. Gundersen C, Engelhard EE, Crumbaugh AS, et al. Brief assessment of food insecurity accurately identifies high-risk US adults. Public Health Nutr 2017; 20(8):1367-1371.

79. Makelarski JA, Abramsohn E, Benjamin JH, et al. Diagnostic Accuracy of Two Food Insecurity Screeners Recommended for Use in Health Care Settings. Am J Public Health 2017; 107(11):1812-1817.

80. Al Hamarneh YN, Charrois T, Lewanczuk R, et al. Pharmacist intervention for glycaemic control in the community (the RxING study). BMJ open 2013; 3(9):e003154.

81. Olsho LE, Klerman JA, Wilde PE, et al. Financial incentives increase fruit and vegetable intake among Supplemental Nutrition Assistance Program participants: a randomized controlled trial of the USDA Healthy Incentives Pilot. Am J Clin Nutr 2016; 104(2):423-435.

82. Browne AJ, Varcoe C, Ford-Gilboe M , et al. EQUIP Healthcare: An overview of a multi-component intervention to enhance equity-oriented care in primary health care settings. International journal for equity in health 2015; 14:152.

83. Frut and vegetable prescription program, 2019. [https://www.wholesomewave.org/]

84. Mayne SL, Auchincloss AH, Michael YL. Impact of policy and built environment changes on obesity-related outcomes: a systematic review of naturally occurring experiments. Obes Rev 2015; 16(5):362-375.

85. McGill R, Anwar E, Orton L, et al. Are interventions to promote healthy eating equally effective for all? Systematic review of socioeconomic inequalities in impact. BMC Public Health 2015; 15(1):457.

86. Ni Mhurchu C, Blakely T, Jiang $Y$, et al. Effects of price discounts and tailored nutrition education on supermarket purchases: a randomized controlled trial. Am J Clin Nutr 2010; 91(3):736-747.

87. Burr ML, Ashfield-Watt PA, Dunstan FD, et al. Lack of benefit of dietary advice to men with angina: results of a controlled trial. European journal of clinical nutrition 2003; 57(2):193-200.

88. Burr ML, Trembeth J, Jones KB , et al. The effects of dietary advice and vouchers on the intake of fruit and fruit juice by pregnant women in a deprived area: a controlled trial. Public Health Nutr 2007; 10(6):559-565.

89. Ness AR, Hughes J, Elwood PC , et al. The long-term effect of dietary advice in men with coronary disease: follow-up of the Diet and Reinfarction trial (DART). European journal of clinical nutrition 2002; 56(6):512-518.

90. Fafard St-Germain AA, Tarasuk V. Prioritization of the essentials in the spending patterns of Canadian households experiencing food insecurity. Public Health Nutr 2018; 21(11):2065-2078. 
91. Khan MI, Weinstock RS: Carbohydrates. In: Henry's Clinical Diagnosis and Management by Laboratory Methods. 22nd edn. Edited by McPherson RA, Pincus MR. Philadephia, PA: Saunders Elsevier; 2011: 210-225.

92. Goddu AP, Roberson TS, Raffel KE, et al. Food Rx: a community-university partnership to prescribe healthy eating on the South Side of Chicago. J Prev Interv Community 2015; 43(2):148-162.

93. Nutrition Guideline Diabetes, 2016. [https://www.albertahealthservices.ca/assets/info/nutrition/if-nfs-ngdiabetes.pdf]

94. Canadian Community Health Survey - Annual Component (CCHS), 2020. [https://www23.statcan.gc.ca/imdb/p3Instr.pl?Function=assemblelnstr\&lang=en\&ltem_ld=1262397]

95. Milton K, Bull FC, Bauman A. Reliability and validity testing of a single-item physical activity measure. British journal of sports medicine 2011; 45(3):203-208.

96. Topp CW, Ostergaard SD, Sondergaard S, et al. The WHO-5 Well-Being Index: a systematic review of the literature. Psychother Psychosom 2015; 84(3):167-176.

97. Lorig K, Stewart A, Ritter P , et al. Outcome Measures for Health Education and Other Health Care Interventions, vol. 2019. Thousand Oaks, CA: Sage; 1996.

98. Self-Efficacy for Diabetes, 2009. [https://www.selfmanagementresource.com/docs/pdfs/English_-_selfefficacy_diabetes.pdf]

99. Schmitt A, Reimer A, Hermanns N, et al. Assessing Diabetes Self-Management with the Diabetes SelfManagement Questionnaire (DSMQ) Can Help Analyse Behavioural Problems Related to Reduced Glycaemic Control. PLoS One 2016; 11(3):e0150774.

100. Schmitt A, Gahr A, Hermanns N, et al. The Diabetes Self-Management Questionnaire (DSMQ): development and evaluation of an instrument to assess diabetes self-care activities associated with glycaemic control. Health Qual Life Outcomes 2013; 11:138.

101. McGuire BE, Morrison TG, Hermanns N , et al. Short-form measures of diabetes-related emotional distress: the Problem Areas in Diabetes Scale (PAID)-5 and PAID-1. Diabetologia 2010; 53(1):66-69.

102. EQ-5D-5L, 2020. [https://euroqol.org/eq-5d-instruments/eq-5d-5I-about/]

103. Work Productivity and Activity Impairment Questionnaire, 2004. [http://www.reillyassociates.net/WPAI_GH.html]

104. Household Food Insecurity in Canada: A Guide to Measurement and Interpretation, 2018. [https://proof.utoronto.ca/wp-content/uploads/2018/11/Household-Food-Insecurity-in-Canada-A-Guide-toMeasurement-and-Interpretation.pdf]

105. Determining food security status, 2012. [https://www.canada.ca/en/health-canada/services/foodnutrition/food-nutrition-surveillance/health-nutrition-surveys/canadian-community-health-surveycchs/household-food-insecurity-canada-overview/determining-food-security-status-food-nutritionsurveillance-health-canada.html]

106. The Household Food Security Survey Module (HFSSM), 2012. [https://www.canada.ca/en/healthcanada/services/food-nutrition/food-nutrition-surveillance/health-nutrition-surveys/canadian-communityhealth-survey-cchs/household-food-insecurity-canada-overview/household-food-security-survey-modulehfssm-health-nutrition-surveys-health-canada.html]

107. Kalichman SC, Amaral CM, Swetzes C , et al. A simple single-item rating scale to measure medication adherence: further evidence for convergent validity. J Int Assoc Physicians AIDS Care (Chic) 2009; 8(6):367- 
374.

108. Seligman HK, Lyles C, Marshall MB , et al. A Pilot Food Bank Intervention Featuring Diabetes-Appropriate Food Improved Glycemic Control Among Clients In Three States. Health Aff (Millwood) 2015; 34(11):1956.

109. Barriers to Care for People with Chronic Health Conditions (BCPCHC), 2011.

[http://www23.statcan.gc.ca/imdb/p2SV.pl?Function=getSurvey\&SDDS=5189]

110. MacArthur Subjective Social Status Scale, 2019.

[https://macses.ucsf.edu/research/psychosocial/subjective.php]

111. Cundiff JM, Smith TW, Uchino BN , et al. Subjective social status: construct validity and associations with psychosocial vulnerability and self-rated health. Int J Behav Med 2013; 20(1):148-158.

112. Hagenaars A, de Vos K. The definition and measurement of poverty. The Journal of Human Resources 1988; 23(2):211-221.

113. Litwin H, Sapir EV. Perceived income adequacy among older adults in 12 countries: findings from the survey of health, ageing, and retirement in Europe. The Gerontologist 2009; 49(3):397-406.

114. Gildner TE, Liebert MA, Capistrant BD , et al. Perceived Income Adequacy and Well-being Among Older Adults in Six Low- and Middle-Income Countries. The journals of gerontology Series B, Psychological sciences and social sciences 2019; 74(3):516-525.

115. Subar AF, Kirkpatrick SI, Mittl B , et al. The Automated Self-Administered 24-hour dietary recall (ASA24): a resource for researchers, clinicians, and educators from the National Cancer Institute. J Acad Nutr Diet 2012; 112(8):1134-1137.

116. Kirkpatrick SI, Subar AF, Douglass D , et al. Performance of the Automated Self-Administered 24-hour Recall relative to a measure of true intakes and to an interviewer-administered 24-h recall. Am J Clin Nutr 2014; 100(1):233-240.

117. ASA24-Canada, 2020. [http://asa24.ca/about.html]

118. Park Y, Dodd KW, Kipnis V , et al. Comparison of self-reported dietary intakes from the Automated SelfAdministered 24-h recall, 4-d food records, and food-frequency questionnaires against recovery biomarkers. Am J Clin Nutr 2018; 107(1):80-93.

119. Thompson FE, Subar AF: Dietary assessment methodology, 3rd ed. In: Nutrition in the prevention and treatment of disease. edn. Edited by Coulston AM, Boushey CJ, Ferruzzi MG. London: Elsevier; 2013: 5-46.

120. Krebs-Smith SM, Pannucci TE, Subar AF , et al. Update of the Healthy Eating Index: HEl-2015. J Acad Nutr Diet 2018; 118(9):1591-1602.

121. Kirkpatrick SI, Reedy J, Krebs-Smith SM , et al. Applications of the Healthy Eating Index for Surveillance, Epidemiology, and Intervention Research: Considerations and Caveats. J Acad Nutr Diet 2018; 118(9):16031621.

122. American Diabetes A. Standards of medical care in diabetes-2007. Diabetes care 2007; 30 Suppl 1:S4-S41.

123. Sacks DB, Arnold M, Bakris GL , et al. Guidelines and recommendations for laboratory analysis in the diagnosis and management of diabetes mellitus. Clin Chem 2011; 57(6):e1-e47.

124. American Diabetes A, European Association for the Study of D, International Federation of Clinical C , et al. Consensus statement on the worldwide standardisation of the HbA1c measurement. Diabetologia 2007; 50(10):2042-2043. 
125. Diabetes Canada Clinical Practice Guidelines Expert C, Berard LD, Siemens R , et al. Monitoring Glycemic Control. Canadian journal of diabetes 2018; 42 Suppl 1:S47-S53.

126. Baker JR, Johnson RN, Scott DJ. Serum fructosamine concentrations in patients with type II (non-insulindependent) diabetes mellitus during changes in management. Br Med J (Clin Res Ed) 1984; 288(6429):14841486.

127. Radtke MD, Pitts SJ, Jahns L , et al. Criterion-Related Validity of Spectroscopy-Based Skin Carotenoid Measurements as a Proxy for Fruit and Vegetable Intake: A Systematic Review. Adv Nutr 2020; 11(5):12821299.

128. Alberta Health Data Asset Directory, 2018. [https://albertarwe.ca/wp-content/uploads/2018/07/AlbertaHealth-Data-Asset-Directory-2018.pdf]

129. Cheng XH, Jo Y, Kim J. Heterogeneous Impact of Supplemental Nutrition Assistance Program Benefit Changes on Food Security by Local Prices. Am J Prev Med 2020; 58(3):e97-e103.

130. Diabetes Canada Clinical Practice Guidelines Expert C, Lipscombe L, Booth G, et al. Pharmacologic Glycemic Management of Type 2 Diabetes in Adults. Canadian journal of diabetes 2018; 42 Suppl 1:S88-S103.

131. Dimitri C, Oberholtzer L, Zive M , et al. Enhancing food security of low-income consumers: an investigation of financial incentives for use at farmers' markets. Food Policy 2015; 52:64-70.

132. An analysis of sample attrition in panel data: The Michigan panel study of income dynamics, 1997. [http://www.nber.org/papers/t0220.pdf]

133. Testing and adjusting for attrition in Household Panel Data, 2011.

[http://www.chronicpoverty.org/publications/details/testing-and-adjusting-for-attrition-in-household-paneldata]

134. Li P, Stuart EA. Best (but oft-forgotten) practices: missing data methods in randomized controlled nutrition trials. Am J Clin Nutr 2019; 109(3):504-508.

135. Scharfstein D, McDermott A, Diaz I, et al. Global sensitivity analysis for repeated measures studies with informative drop-out: A semi-parametric approach. Biometrics 2018; 74(1):207-219.

136. Damschroder LJ, Aron DC, Keith RE , et al. Fostering implementation of health services research findings into practice: a consolidated framework for advancing implementation science. Implement Sci 2009; 4:50.

137. Meyers DC, Durlak JA, Wandersman A. The quality implementation framework: a synthesis of critical steps in the implementation process. Am J Community Psychol 2012; 50(3-4):462-480.

138. Meyers DC, Katz J, Chien V , et al. Practical implementation science: developing and piloting the quality implementation tool. Am J Community Psychol 2012; 50(3-4):481-496.

139. Indigenous Peoples in Canada Video and Leaning Series, 2019. [https://www.albertahealthservices.ca/info/page7634.aspx]

140. Equipping for equity online modules, 2019. [https://equiphealthcare.ca/toolkit/]

141. Lewis CC, Scott K, Marriott BR. A methodology for generating a tailored implementation blueprint: an exemplar from a youth residential setting. Implement Sci 2018; 13(1):68.

142. CFIR stakeholder survey, 2019. [https://cfirguide.org/evaluation-design/overview/]

143. Powell BJ, Waltz TJ, Chinman MJ , et al. A refined compilation of implementation strategies: results from the Expert Recommendations for Implementing Change (ERIC) project. Implement Sci 2015; 10:21. 
144. Powell BJ, Beidas RS, Lewis CC , et al. Methods to Improve the Selection and Tailoring of Implementation Strategies. J Behav Health Serv Res 2017; 44(2):177-194.

145. Waltz TJ, Powell BJ, Fernandez ME, et al. Choosing implementation strategies to address contextual barriers: diversity in recommendations and future directions. Implement Sci 2019; 14(1):42.

146. Lavis JN, Boyko JA, Gauvin FP. Evaluating deliberative dialogues focussed on healthy public policy. BMC Public Health 2014; $14: 1287$.

147. Lavis JN, Boyko JA, Oxman AD, et al. SUPPORT Tools for evidence-informed health Policymaking (STP) 14: Organising and using policy dialogues to support evidence-informed policymaking. Health Res Policy Syst 2009; 7 Suppl 1:S14.

148. Hsieh HF, Shannon SE. Three approaches to qualitative content analysis. Qual Health Res 2005; 15(9):12771288.

149. Malterud K, Siersma VD, Guassora AD. Sample Size in Qualitative Interview Studies: Guided by Information Power. Qual Health Res 2015.

150. Palinkas LA, Mendon SJ, Hamilton AB. Innovations in Mixed Methods Evaluations. Annu Rev Public Health $2019 ; 40: 423-442$.

151. Alberta wage and salary survey, 2017. [https://www.alberta.ca/wage-salary-information.aspx\#toc-1]

152. Hayes AJ, Leal J, Gray AM , et al. UKPDS outcomes model 2: a new version of a model to simulate lifetime health outcomes of patients with type 2 diabetes mellitus using data from the 30 year United Kingdom Prospective Diabetes Study: UKPDS 82. Diabetologia 2013; 56(9):1925-1933.

153. EQ-5D, 2019. [https://euroqol.org/]

154. Food Security and Diabetes: A Position Statement, 2020. [https://www.diabetes.ca/en-CA/advocacy-policies/our-policy-positions/food-security-and-diabetes?

utm_source=eBlast_June2020\&utm_medium=eblast\&utm_campaign=newsletter\&utm_content=hyperlink_txt]

155. Morton S. Progressing research impact assessment: A 'contributions' approach. Research Evaluation 2015; 24:405-419.

156. Moscrop A, Ziebland S, Roberts N , et al. A systematic review of reasons for and against asking patients about their socioeconomic contexts. International journal for equity in health 2019; 18(1):112.

157. We ask because we care. The Tri-Hospital + TPH Health Equity Data Collection Research Project Report, 2018. [http://www.stmichaelshospital.com/quality/equity-data-collection-report.pdf]

158. Naz A, Rosenberg E, Andersson N, et al. Health workers who ask about social determinants of health are more likely to report helping patients: Mixed-methods study. Can Fam Physician 2016; 62(11):e684-e693.

159. Health Care's Blind Side. The overlooked connection between social needs and good health., 2011. [https://www.rwjf.org/en/library/articles-and-news/2011/12/health-cares-blind-side-unmet-social-needsleading-to-worse-heal.html]

160. Anderson ES, Lippert S, Newberry J , et al. Addressing Social Determinants of Health from the Emergency Department through Social Emergency Medicine. West J Emerg Med 2016; 17(4):487-489.

161. Schickedanz A, Hamity C, Rogers A, et al. Clinician Experiences and Attitudes Regarding Screening for Social Determinants of Health in a Large Integrated Health System. Medical care 2019; 57 Suppl 6 Suppl 2:S197S201. 
162. Collaborators GBDD. Health effects of dietary risks in 195 countries, 1990-2017: a systematic analysis for the Global Burden of Disease Study 2017. Lancet 2019; 393(10184):1958-1972.

163. Tarasuk V, Cheng J, de Oliveira $C$, et al. Association between household food insecurity and annual health care costs. Cdn Med Assoc J 2015; 187(14):E429-E436.

164. Fitzpatrick C, Datta GD, Henderson M , et al. School food environments associated with adiposity in Canadian children. Int J Obes (Lond) 2017; 41(7):1005-1010.

165. Campbell DJ, Manns BJ, Weaver RG, et al. Financial barriers and adverse clinical outcomes among patients with cardiovascular-related chronic diseases: a cohort study. BMC medicine 2017; 15(1):33.

166. Canadian Community Health Survey Public Use Microdata Files, 2015-16. [ https://www-statcan-gcca.ezproxy.lib.ucalgary.ca/eng/reference/licence]

167. Tonelli M, Wiebe N, Richard JF , et al. Characteristics of Adults With Type 2 Diabetes Mellitus by Category of Chronic Kidney Disease and Presence of Cardiovascular Disease in Alberta Canada: A Cross-Sectional Study. Can J Kidney Health Dis 2019; 6:2054358119854113.

168. First Nations Food, Nutrition \& Environment Study, 2019. [http://www.fnfnes.ca/]

169. Galesloot S, Mclntyre L, Fenton T, et al. Food insecurity in Canadian adults receiving diabetes care. Can J Diet Pract Res 2012; 73(3):e261-266.

170. Juarez D, Goo R, Tokumaru S , et al. Association Between Sustained Glycated Hemoglobin Control and Healthcare Costs. Am J Pharm Benefits 2013; 5(2):59-64.

\section{Table}

Due to technical limitations, table 1 is only available as a download in the Supplemental Files section.

\section{Figures}

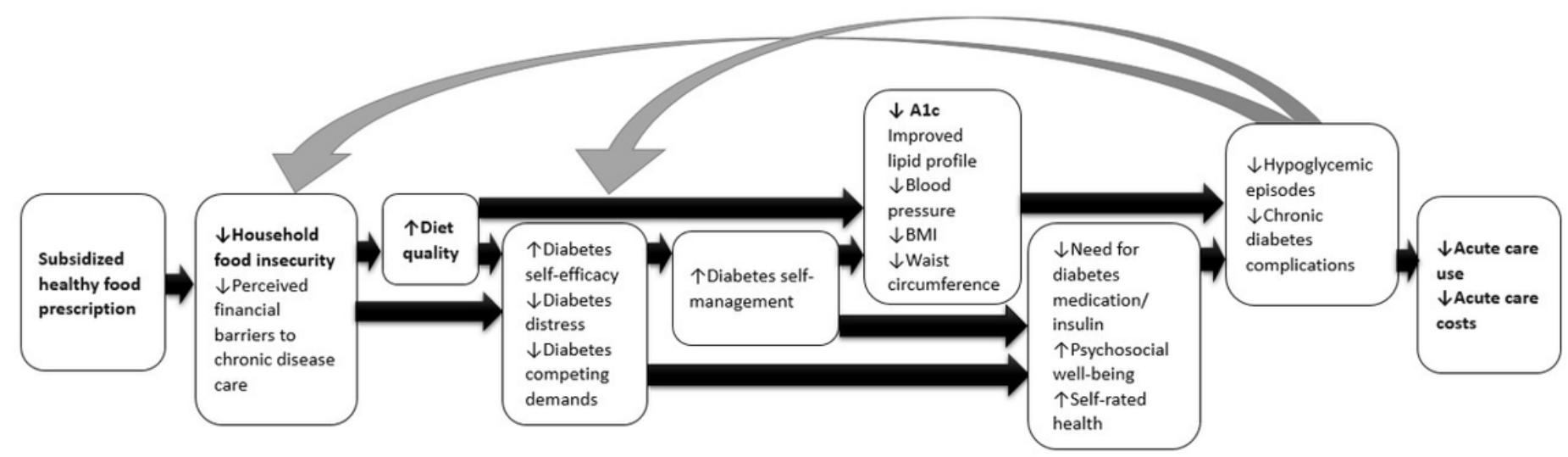

Figure 1

Healthy food prescription program logic model 


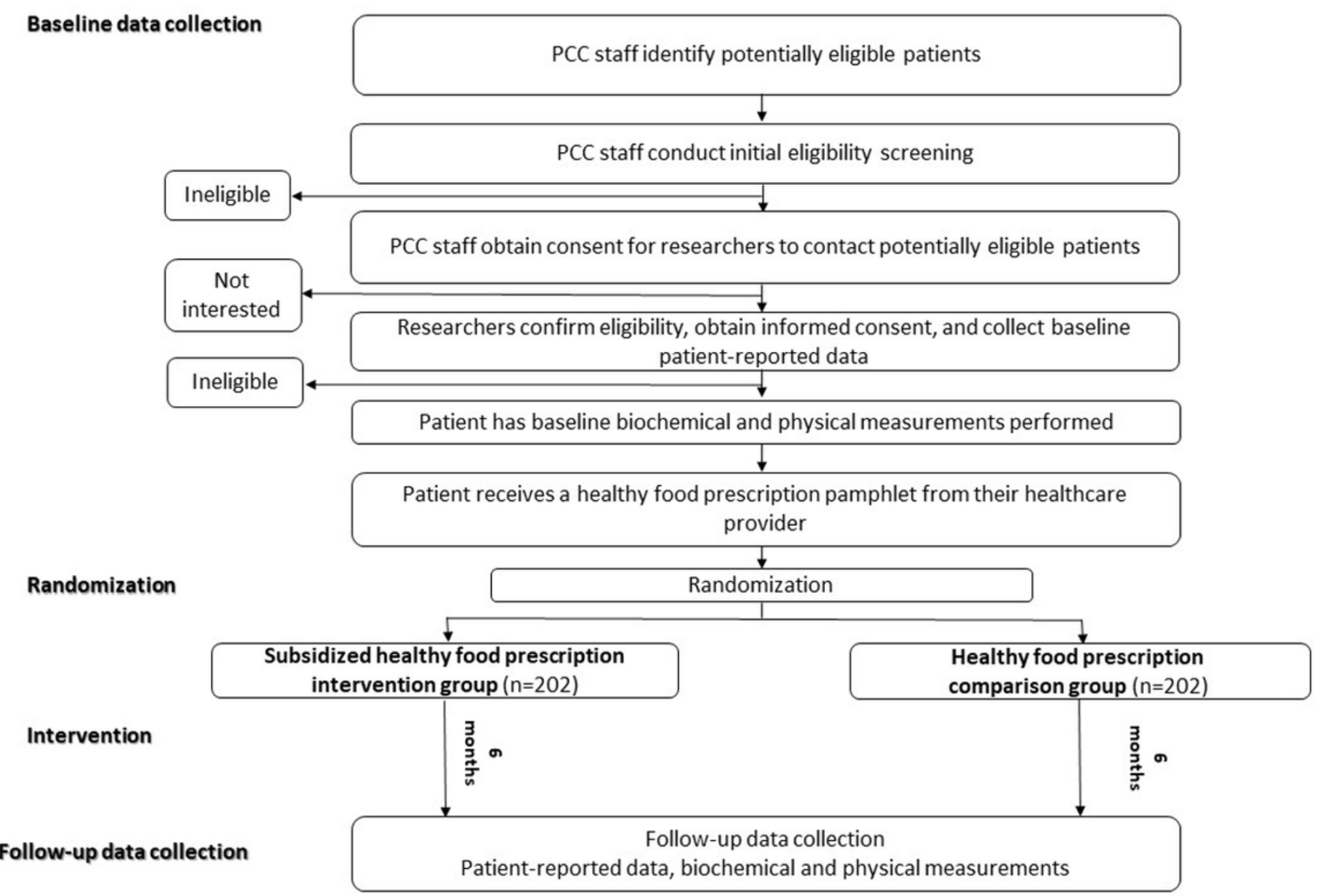

Figure 2

Healthy food prescription program care pathway PCC: Primary care clinic

\section{Supplementary Files}

This is a list of supplementary files associated with this preprint. Click to download.

- Additionalfile1FoodRxRCTConsent.docx

- Additionalfile2SPIRITFoodRx.doc

- Additionalfile3WHOdataset.docx

- Additionalfile4TIDieRChecklist.docx

- AdditionalFile5FoodRx.pdf

- Table1SPIRITflowdiagram.docx 